\title{
de Virgílio Borges Pereira, Classes e culturas de classe das familias portuenses: \\ Classes sociais e modalidades de estilização da vida na cidade do Porto
}

(Porto, Afrontamento, 2005).

João Valente Aguiar

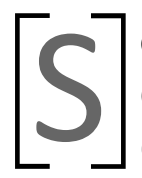

erá possível que uma obra sociológica, produzida num determinado contexto, apresente propriedades aplicáveis numa outra situação social específica? Estamos em crer que a obra de Virgílio Borges Pereira aqui em breve análise permite responder afirmativamente a esta questão. De facto, este é um extenso trabalho de pesquisa sobre um cenário social e espacial específico - classes, famílias e estilos de vida presentes na cidade do Porto, a segunda maior cidade portuguesa - mas com um percurso metodológico e um quadro teórico accionados com elevada pertinência para compreender dinâmicas sociais inscritas na sociedade brasileira. Aliás, numa era marcada pela difusão da internet e das tecnologias da informação, o contacto com obras e projectos de pesquisa de outros continentes surge como uma possibilidade real e uma forma de potenciar o intercâmbio científico.

Classes e culturas de classe... abarca três partes, cada uma delas abordando dimensões distintas. A primeira parte convoca a teoria da prática do sociólogo francês Pierre Bourdieu para dar conta do que este autor denomina de "dupla relação obscura entre os habitus e os campos, (...) tudo o que surge dessa relação, quer dizer as práticas e as representações sociais ou os campos" (Bourdieu apud Pereira, 2005, p.29). De facto, é da análise da famosa dialéctica bourdiana da interiorização da exterioridade (os processos de socialização humana) e da exteriorização da interioridade (a projecção do agente social na sociedade) que se desdobra toda a obra de Virgílio Borges Pereira. Assim, o estudo do autor na cidade do Porto trabalha afincadamente a produção das práticas, a "produção do quotidiano" (Pereira: 35) pelas classes sociais, nomeadamente na relação que elas estabelecem com o tempo de trabalho e com o tempo de lazer (idem: 36-41). Pereira congrega, dessa forma, um arguto olhar sociológico sobre as classes sociais como um conceito que mantém uma forte pertinência analítica. Realizando um frutí- 
fero confronto de perspectivas sobre esse conceito - dialogando com a escola lisboeta das classes sociais de João Ferreira de Almeida e de António Firmino da Costa, mas também com Mike Savage, Crompton, Goldthorpe e Bourdieu - o autor vai apresentar as classes sociais como "colectividades sociais dotadas de estabilidade económica, social e política aptas a serem estudadas sob pontos de vista que acentuam a importância dos respectivos processos de formação histórica (e) quotidiana" (ibidem: 48). O sociólogo português coloca aqui em foco duas dimensões. Por um lado, a produção da vida quotidiana, dos seus consumos e suas práticas, aporta condicionantes de classe. Por outro lado, a importância das classes sociais na estruturação de comportamentos sociais comporta regularidades (e naturalmente excepções), dando conta de um pensar sociológico que não caia no relativismo indiferencial. Quer dizer, recusando o indeterminismo do indivíduo isolado, como se este fosse a única fonte do agir humano em sociedade. Nesse sentido, Virgílio Borges Pereira apresenta o objectivo central da sua pesquisa:

conhecer as diferentes relações quotidianas que os agentes sociais (re)produzem com os diferentes campos do social e, nessa medida, destacar a importância dos quadros mais sistemáticos de regularidades económicas, escolares, culturais, relacionais e simbólico-ideológicas a que tais relações se sujeitam e estão sujeitas, em particular, as que são formadas quotidianamente tendo o espaço das classes sociais e das fracções de classe como referência socializadora (ibidem: 53-54).

Esta transcrição é longa, mas afigura-se como útil na exposição da densidade dos enunciados aplicados pelo autor na sua pesquisa.

A segunda parte sugestivamente intitulada "Classes, quotidianos e representações" (ibidem: 111-478) congrega alguns vectores de análise empírica de grande relevo. A este título, Virgílio Borges Pereira sublinha aspectos da caracterização do espaço social portuense tais como o perfil das actividades económicas da cidade, as qualificações escolares da sua população ou a composição social e demográfica das famílias portuenses (ibidem: 144-150). Subsequentemente, o autor envereda pela classificação das "capitalizações no quotidiano" (ibidem: 170-175), sobretudo no que mais diz respeito no acesso das diferentes classes e fracções de classe a bens e equipamentos, realizando uma tripla leitura aos capitais económico, cultural e social das famílias portuenses a partir de dados oficiais do Estado português. Neste tópico entram em consideração, respectivamente, o volume de rendimen- 
tos e a natureza do vínculo de trabalho; o número de livros em casa; as redes relacionais dos agentes e das suas famílias, entre outros eixos contemplados. Depois dessa breve caracterização da estrutura de capitais da cidade, Pereira empreende uma incursão nas formas como se expressam os estilos de vida. Estilos de vida que se ancoram nas relações de classe e que o autor desdobrou em três patamares: 1 . vivências quotidianas em contexto doméstico onde podemos encontrar o estudo de lazeres domésticos receptivos (ver televisão, por exemplo) e de lazeres domésticos expressivos (tocar instrumentos musicais ou trabalhos manuais com baixa expressão na cidade); 2 . vivências quotidianas em contexto local, com particular realce para as actividades públicas de lazer sociável na vizinhança do local de residência, as actividades semipúblicas (como tomar café ou jantar fora); e 3. vivências quotidianas em contexto urbano, em que se nota um relevo forte e ritualizado em novos locais de consumo (centros comerciais, idas ao hipermercado) e as selectivas sociabilidades no frequentar de tabernas, de discotecas ou em determinados restaurantes da cidade.

Contudo, o que de mais relevante se pode encontrar na parte II de Classes e culturas de classe... consubstancia-se no estudo sobre as relações entre práticas e representações. De acordo com Pereira, os "processos de tomada de posição dos agentes sociais na cidade do Porto" (ibidem: 357) passam pela inserção do estudo das classes sociais, não somente a partir de considerações materiais e estruturais (actividade profissional e rendimento económico) considerações inescapáveis para uma análise fecunda das classes sociais mas, por si só, insuficientes - mas também a partir das redes de amizade, do uso do(s) tempo(s) de lazer, do variável grau de proximidade entre os espaços de sociabilidades e o local de residência. Paralelamente, também entram no esquema de análise as relações complexas e multidimensionais entre associativismo sindical e partidária, a socialização religiosa e a classe social.

A parte III de Classes e culturas de classe... sugere uma investida por uma variável de inegável interesse nas ciências sociais: o espaço. Aí, Pereira trata da materialização de dinâmicas sociais e culturais no território físico. Para isso o autor recorre a quatro estudos de caso de outros tantos espaços típicos da cidade do Porto.

O primeiro espaço reporta-se ao morro da Vitória, uma zona situada em pleno centro histórico daquela cidade. Da sua pesquisa de campo, Virgílio Borges Pereira retira a conclusão de que esse é um espaço com fortes traços de uma população envelhecida. Ao nível do mapeamento das classes so- 
ciais o autor regista a presença de $34 \%$ de operários e de $36 \%$ de indivíduos pertencentes à pequena-burguesia de execução (ibidem: 498-499). As sociabilidades e as dinâmicas mais especificamente vinculadas com os capitais escolares e culturais ali encontradas são pautadas por baixos níveis de literacia ( $74 \%$ da população do morro não tem mais do que seis anos completos de escolaridade e $41 \%$ têm menos de 10 livros em casa, dos quais mais de $25 \%$ não têm qualquer livro) (ibidem: 509). Em termos de votação eleitoral, encontra-se naquele território da cidade do Porto, uma forte votação em partidos de esquerda (78\% distribuídos por quatro forças políticas dessa tendência).

Um segundo caso se articula em torno de Cedofeita, um espaço do centro da cidade distinto do anterior e fortemente atravessado por dinâmicas de "terciarização da actividade económica" (ibidem: 559) e de individualização. Em Cedofeita, cerca de $67 \%$ da população ocupa um lugar de classe dentro das várias fracções da pequena-burguesia, onde a pequena-burguesia intelectual ou a pequena-burguesia técnica e de enquadramento representam metade do contingente da classe dentro desse espaço. Por seu turno, o operariado tem uma presença diminuta não indo além dos $5 \%$. A burguesia empresarial e dirigente e os gestores correspondem a $15 \%$ da população daquela zona do Porto (ibidem: 566-567). Ao inverso do caso anterior, o capital escolar aqui encontrado é elevado, na medida em que mais de metade da população, pelo menos concluiu o ensino secundário. No respeitante ao capital cultural Pereira encontrou dinâmicas que apontam para

um mais intenso desenvolvimento de actividades mais ou menos regulares de estudo, a prática semanal da leitura de livros, a entrega às actividades da cozinha várias vezes por semana, uma intensa actividade relacional de recepção de amigos (ibidem: 577).

Em termos de voto político, encontra-se um equilíbrio mais ou menos idêntico ao que acontece na votação nacional entre os dois maiores partidos portugueses (PS e PSD), ao mesmo tempo que a extrema-esquerda de origem trotsquista tem quase $9 \%$ dos votos recolhidos em Cedofeita (ibidem: 611). Votação com claros contornos de juvenilidade e de conexão com profissões do meio artístico.

O terceiro caso - o bairro do Viso - congrega vectores presentes, parcialmente no morro da Vitória. Contudo, no Viso encontramos uma população relativamente constante (numérica e socialmente) na medida em que esse 
é um aglomerado habitacional construído pela Câmara Municipal do Porto (a Prefeitura) nos anos 1970. Assim, encontram-se ali fortes índices de vulnerabilidade social e laboral. Nesse capítulo, 38\% da população do bairro desempenham funções de serviços mal remunerados e muito ligados a tarefas no comércio ou em serviços de limpeza. O operariado industrial congrega $40 \%$ da população do bairro (ibidem: 630). O capital escolar é baixo mas ligeiramente superior ao vislumbrado na Vitória: quase $75 \%$ da população tem menos de nove anos completos de escolaridade, um patamar de qualificação académica incapaz de alçar aquela população para o seio de processos de mobilidade social ascendente (ibidem: 637). Politicamente, o bairro é claramente maioritário na votação no Partido Socialista (mais de $60 \%$ ) e onde os votos em branco têm uma elevada percentagem (mais de 11\%) (ibidem: 680).

Finalmente, na chamada faixa atlântica portuense - "território de eleição das classes mais dotadas em privilégios" (ibidem: 698) onde a burguesia empresarial e a burguesia dirigente representam mais de um quarto da população local e onde a pequena-burguesia intelectual e de enquadramento é mais de $39 \%$ da população - exerce-se uma "lógica de acumulação de posicionamentos privilegiados no espaço social" (ibidem: 706). Em termos de capital escolar, cerca de $24 \%$ têm ensino superior completo (ibidem: 707) e onde a frequência a concertos de música clássica, ao teatro, ao ballet ou a museus e exposições de arte é sumamente superior relativamente à média da população da cidade (ibidem: 730-731). Pereira corrobora ainda diferenças substantivas dentro das classes dominantes da cidade no que diz respeito à apropriação de bens e espaços culturais, precisamente entre uma camada de gestores e dirigentes de empresas predominantemente aristocratizados e com um habitus de classe muito próximo da distinção apresentada por Bourdieu no seu livro homónimo e uma burguesia empresarial tendencialmente composta por agentes sociais mais jovens e com um sentimento e uma cultura de classe predominantemente virada para consumos alternativos e formas de convivialidade mais abertas e públicas. Do ponto de vista político, o voto à direita é nítido e a própria militância nos partidos de direita (PSD e CDS/PP) e nas associações empresariais e patronais reveste-se como um facto de elevada importância para a compreensão das disposições políticas da burguesia portuense.

O autor constrói, assim, o seu quadro analítico e de pesquisa partindo do pressuposto que o enraizamento das classes sociais não subtrai a necessidade de compreensão das igualmente estruturantes redes de interacção 
social e cultural na consolidação e reprodução das classes sociais. Ou seja, para utilizar uma exemplificação de Classes e culturas de classe..., a pertença económica à grande burguesia portuense fomenta a adopção de posturas conservadoras no tocante à necessidade que os indivíduos dessa classe social têm em reproduzir o seu património financeiro e imobiliário. Contudo, tanto a posição económica de classe determina comportamentos políticos e ideológicos tendencialmente conservadores, como, em simultâneo, a profusão de redes de sociabilidade e de múltiplos instrumentos de socialização das crianças e jovens nascidos no seio de famílias dessa classe social contribuem fortemente para um constante e recorrente processo de aprendizagem social das diferenças de classe e de estatuto. Também por estes processos os (jovens) elementos da burguesia apre(e)ndem a necessidade de respeitar a ordem vigente e da adequação de predisposições conservadoras ao seu modo de vida. Ao mesmo tempo, importa ressalvar que apesar de neste estudo o impacto da variável classe social na estruturação dos comportamentos dos agentes sociais ser considerável, ele nunca é assumido de um modo uni-causal ou exclusivo. Como se procurou demonstrar, a classe social interactua com o território e com a produção de subjectividade.

Em síntese, esta obra de Virgílio Borges Pereira apresenta um conjunto de coordenadas de elevada densidade e de relevante capacidade de induzir fecundas incursões sociológicas em territórios urbanos. Articulando criativamente os conceitos de classe social, território e cultura (e em que este último se desdobra nas categorias de sociabilidade, socialização e estilos de vida) e conseguindo relacionar consequentemente o quadro teórico com a metodologia de recolha, tratamento e análise do real-social concreto, Classes e culturas de classe... representa um exercício sociológico de grande pertinência para investidas nas áreas da sociologia das classes sociais, da sociologia urbana e da sociologia da cultura. Também por esta estimulante objectivação transdisciplinar o livro de Virgílio Borges Pereira é uma obra a merecer ser lida e estudada. 